\title{
Bronchial hyperresponsiveness, airway inflammation, and reversibility in patients with chronic obstructive pulmonary disease
}

This article was published in the following Dove Press journal:

International Journal of COPD

17 June 2015

Number of times this article has been viewed

\author{
Andrea Zanini' \\ Francesca Cherubino' \\ Elisabetta Zampogna' \\ Stefania Croce ${ }^{2}$ \\ Patrizia Pignatti ${ }^{2}$ \\ Antonio Spanevello 3 \\ 'Division of Pneumology, IRCCS \\ Rehabilitation Institute of Tradate, \\ Salvatore Maugeri Foundation \\ (IRCCS), Tradate, Italy; ${ }^{2}$ Allergy \\ and Immunology Unit, Salvatore \\ Maugeri Foundation (IRCCS), Pavia, \\ Italy; ${ }^{3}$ Department of Clinical and \\ Experimental Medicine, University \\ of Insubria, Varese, Italy
}

Background: Bronchial hyperresponsiveness (BHR), sputum eosinophilia, and bronchial reversibility are often thought to be a hallmark of asthma, yet it has been shown to occur in COPD as well.

Objectives: To evaluate the relationship between BHR, lung function, and airway inflammation in COPD patients.

Methods: Thirty-one, steroid-free patients with stable, mild and moderate COPD were studied. The following tests were carried out: baseline lung function, reversibility, provocative dose of methacholine causing a $20 \%$ fall in forced expiratory volume in 1 second, a COPD symptom score, and sputum induction.

Results: Twenty-nine patients completed the procedures. About $41.4 \%$ had BHR, 31.0\% had increased sputum eosinophils, and $37.9 \%$ had bronchial reversibility. Some of the patients had only one of these characteristics while others had two or the three of them. Patients with BHR had higher sputum eosinophils than patients without BHR $(P=0.046)$ and those with sputum eosinophils $\geq 3 \%$ had more exacerbations in the previous year and a higher COPD symptom score than patients with sputum eosinophils $<3 \%$ ( $P=0.019$ and $P=0.031$, respectively). In patients with BHR, the cumulative dose of methacholine was negatively related to the symptom score and the number of exacerbations in the previous year. When patients with bronchial reversibility were considered, bronchodilation was positively related to sputum eosinophils.

Conclusion: Our study showed that BHR, sputum eosinophilia, and bronchial reversibility were not clustered in one single phenotype of COPD but could be present alone or together. Of interest, BHR and airway eosinophilia were associated with clinical data in terms of exacerbations and symptoms. Further investigation is needed to clarify this topic.

Keywords: hyperreactivity, methacholine, exacerbations, sputum eosinophilia, COPD

\section{Introduction}

Bronchial hyperresponsiveness (BHR) is a common characteristic of asthmatic subjects, but it is also present in COPD patients and in $11 \%-20 \%$ of healthy subjects. ${ }^{1}$ In the "Sapaldia" study, 17\% of the randomly enrolled Swiss subjects had BHR and $51 \%$ of them were asymptomatic. ${ }^{2}$ After 11 years, some of these subjects were reevaluated, showing that BHR is a risk factor for a rapid forced expiratory volume in 1 second $\left(\mathrm{FEV}_{1}\right)$ decline and for asthma and COPD development. ${ }^{2}$

BHR is often associated with bronchial inflammation, particularly in asthmatic subjects, ${ }^{3}$ but different studies also demonstrated a dissociation between BHR and airway inflammation in asthma. ${ }^{4}$ Moreover, smoking is a risk factor for BHR increasing over time ${ }^{5}$ and BHR improves after smoking cessation. ${ }^{6}$
Correspondence: Andrea Zanin

Division of Pneumology, IRCCS

Rehabilitation Institute of Tradate,

Salvatore Maugeri Foundation (IRCCS),

Via Roncaccio 16, 21049 Tradate, Italy

Tel +390331829 III

$\mathrm{Fax}+390331829417$

Email azanini67@gmail.com 
While a predominant characteristic of asthma, BHR can be present in up to two-thirds of COPD patients ${ }^{7}$ as an independent trait and can be useful to phenotype COPD patients. ${ }^{8}$ COPD patients are also characterized by an increased airway inflammation, mainly neutrophilic with recruitment also of CD8 T-lymphocytes. ${ }^{9,10}$ Sputum eosinophils, which are very frequently increased in asthmatic airways, are also elevated in a subgroup of COPD patients, particularly during the exacerbation of the disease. ${ }^{11,12}$

Bronchodilator reversibility, which has been considered as one of the characteristics of asthmatic subjects, can also be present in COPD patients, despite a great intrasubject variability. ${ }^{13}$ Papi et $\mathrm{al}^{14}$ found an increase of sputum eosinophils in COPD subjects with partial reversibility, while Dima et $\mathrm{al}^{15}$ did not find any differences in sputum cell infiltrate between COPD with or without reversibility. The heterogeneity of COPD patients has recently been highlighted by many studies attempting to discriminate different COPD phenotypes. ${ }^{16-21}$

The aim of our study was to evaluate sputum airway inflammation, BHR, and bronchodilator reversibility in a group of mild and moderate COPD patients. To the best of our knowledge, many studies described these characteristics of COPD patients, but none of them considered the three characteristics together.

\section{Methods}

\section{Subjects}

Thirty-one subjects with stable, mild and moderate COPD were enrolled in the study, and induced sputum evaluation was successful in 29 patients. The enrolled subjects were diagnosed according to the GOLD (global initiative for chronic obstructive lung disease) criteria, which included a post-bronchodilator spirometry to confirm airflow obstruction, in an evocative clinical context (dyspnea, chronic cough or sputum production, and a history of exposure to risk factors for the disease). ${ }^{22}$ They received COPD diagnosis 4 years ( \pm 3 years) before enrollment in the study. The subjects were indicated as "mild and moderate" in reference to the spirometric classification of GOLD guidelines (GOLD 1 and 2 stages). None of the subjects had a history of asthma, or previous doctor-diagnosed asthma, and allergies or a family history of asthma. All subjects were steroid-free for at least 1 month. None of the patients reported infections of the upper respiratory tract or exacerbations in the previous 2 months. All patients had a more than 10 pack-years history of smoking and were treated with inhaled long acting bronchodilators and inhaled salbutamol as needed: tiotropium $(n=6)$, tiotropium and indacaterol $(\mathrm{n}=12)$, glycopyrronium and indacaterol $(n=5)$, tiotropium and salmeterol $(n=5)$, and tiotropium and formoterol $(n=1)$. Patients were informed about the methodology and the aim of the study and gave written informed consent to enter the study. All subjects were outpatients and recruited in the Division of Pneumology of the IRCCS Rehabilitation Institute of Salvatore Maugeri Foundation, Tradate, Italy. This study conformed to the declaration of Helsinki and was approved by the Institutional Review Board of the Salvatore Maugeri Foundation.

\section{Study design}

In ambulatory environment, patient's medical history was taken and physical examination, and spirometry with bronchial reversibility was carried out. Then, the subjects included in the study attended the laboratory on two different sessions within 1 week: during the first session they were asked to complete the COPD symptoms questionnaire ${ }^{23}$ and they underwent the methacholine challenge; during the second session the sputum induction was carried out.

Although all patients denied a clinical history of allergic diseases; atopy was excluded by skin prick tests with a battery of the most common inhalant allergens (Lofarma S.P.A, Milano, Italy).

\section{Pulmonary function tests}

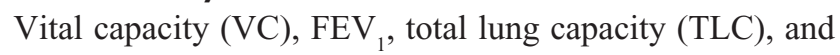
residual volume (RV), were measured by means of a flowsensing spirometer and a body plethysmograph connected to a computer for data analysis (Masterlab, Jaeger, Wurzburg, Germany). Bronchial reversibility after $400 \mu \mathrm{g}$ of inhaled salbutamol was also evaluated. Changes in $\mathrm{FEV}_{1}$ and/or $\mathrm{VC}>12 \%$ and $200 \mathrm{~mL}$ compared with baseline were considered to identify a positive bronchodilator response. ${ }^{24} \mathrm{VC}$, $\mathrm{FEV}_{1}$, TLC, RV, and transfer factor of the lung for carbon monoxide $\left(\mathrm{TL}_{\mathrm{CO}}\right)$ were expressed as percentages of the predicted values, which were obtained from regression equations by Quanjer et $\mathrm{al}^{25}$ and Cotes et $\mathrm{al}^{26} \mathrm{FEV}_{1} / \mathrm{VC}$ and RV/TLC ratios were considered as indices of airway obstruction and lung hyperinflation, respectively.

\section{COPD symptoms questionnaire}

A COPD symptoms questionnaire ${ }^{23}$ was completed by patients to capture the severity of early-morning and nighttime symptoms (5-point scale: $1=$ "did not experience symptoms"; 5= "very severe"), and individual morning symptoms of cough, wheeze, shortness of breath, and phlegm (5-point scale: $0=$ "no symptoms"; 4= "very severe symptoms"), as well as limitations of morning activities (5-point 
scale: $1=$ "not at all"; 5= "a very good deal") and frequency of nocturnal awakenings as a result of COPD symptoms. Similar to the number of exacerbations, the evaluation of COPD symptoms questionnaire referred to the previous year. We asked the patients to answer the questionnaire, trying to consider the presence of symptoms over the last year. Then, we obtained seven partial scores (severity of early-morning and of nighttime symptoms; individual morning symptoms of cough, wheeze, shortness of breath, and phlegm; and limitations of morning activities) to calculate the final score.

\section{Methacholine challenge}

Methacholine inhalation challenge was done according to the European Respiratory Society (ERS) guidelines. ${ }^{27}$ The test was performed by measuring the cumulative dose of inhaled methacholine, by using the Aerosol Provocation System (Jaeger, Wurzburg, Germany). Inhalation was interrupted when $\mathrm{FEV}_{1}$ decreased by $20 \%$ from its baseline value. The cumulative dose causing a $20 \%$ decrease in $\mathrm{FEV}_{1}\left(\mathrm{PD}_{20}\right.$ [provocative dose] methacholine in $\mu \mathrm{g}$ ) was determined by means of linear interpolation of the last two experimental points.

\section{Sputum induction and analysis}

Sputum was induced by inhalation of hypertonic saline aerosol and processed as described previously. ${ }^{28}$ Briefly, 10 minutes after salbutamol inhalation $(200 \mu \mathrm{g})$, hypertonic saline $(4.5 \%)$, nebulized by an ultrasonic nebulizer (ULTRA-NEB 3000, DeVilbiss Healthcare Inc, Somerset, PA, USA), was inhaled over different time periods. Then the patient was invited to cough and sputum was collected. $\mathrm{FEV}_{1}$ was monitored before and after each inhalation, to either prevent or detect possible bronchoconstriction (Pony FX Spirometer, Cosmed, Chicago, IL, USA). After collection, the sputum sample was processed within 2 hours, according to ERS standardized method, with dithiothreitol and then centrifuged at $1,000 \times g$ for 5 minutes. ${ }^{29}$ The cell pellet was resuspended in a volume of phosphate-buffered saline equal to that of the filtered suspension. The total cell count was determined by using a Burker chamber. The cell suspension was then centrifuged at $450 \mathrm{rpm}$ for 6 minutes (Shandon 3 Cytocentrifuge; Shandon Southern Instruments, Sewickley, PA, USA). Two cytospin slides were stained with Diff-Quick solutions (Medion Diagnostics AG, Düdingen, Switzerland) for differential cell count. Only samples with less than $20 \%$ squamous epithelial cells and viability exceeding 50\% were considered idoneous. Sputum eosinophilia was defined when a percentage of sputum eosinophils $\geq 3 \%$ occurred. ${ }^{28}$

\section{Statistical analysis}

Values are presented as mean \pm standard deviation or median (interquartile range). Differences between groups were analyzed by the nonparametric Mann-Whitney $U$-test and by chisquare test. Relationships were estimated by the Spearman's rank correlation coefficient $\left(r_{\mathrm{s}}\right)$. Data analyses and graphical presentations were performed using GraphPad Prism 5 (GraphPad Software, San Diego, CA, USA). A $P$-value $<0.05$ was considered as significant.

\section{Results}

Clinical and functional characteristics of patients with COPD are reported in Table 1. Data of induced sputum cells are shown in Table 2.

About $41.3 \%$ of the COPD patients had BHR, 31.0\% had sputum eosinophilia, and $37.8 \%$ had bronchodilator reversibility. Some of the patients had only one of these characteristics while others two or the three of them, as shown in Figure 1.

Patients with BHR had significantly higher hyperinflation (RV) than those without BHR ( $168 \pm 36$ vs $146 \pm 40, P=0.024)$, and higher sputum eosinophils $(P=0.046)$ (Table 2$)$. Six out of 12 patients with BHR and 2 out of 17 patients without BHR had increased sputum eosinophils $(P=0.014)$. Moreover,

Table I Clinical and functional characteristics of the studied patients

\begin{tabular}{ll}
\hline & COPD patients (n=29) \\
\hline Age (years) & $67 \pm 9$ \\
Sex (female/male) & $6 / 23$ \\
Current smoker, n (\%) & $13(45)$ \\
Smoking consumption (pack/year) & $51 \pm 34$ \\
FEV (\% predicted) & $68 \pm 17$ \\
VC (\% predicted) & $98 \pm 14$ \\
FEV, $/$ C (\%) & $54 \pm 10$ \\
RV (\% predicted) & $155 \pm 39$ \\
TLC (\% predicted) & $118 \pm 17$ \\
RV/TLC (\%) & $51 \pm 7$ \\
IC (L) & $2.6 \pm 0.4$ \\
Change in FEV,$(\%)$ & $8.6 \pm 8.5$ \\
BMI (kg/m ${ }^{2}$ ) & $27 \pm 4$ \\
Exacerbations previous year & $0.7 \pm 0.8$ \\
Symptom score & $8.1 \pm 4.2$ \\
Cough & $21 / 29$ \\
Wheezing & $8 / 29$ \\
Dyspnea & $15 / 29$ \\
Sputum & $24 / 29$ \\
Nocturnal symptoms & $10 / 29$ \\
\hline
\end{tabular}

Note: Values are expressed as mean \pm SD

Abbreviations: $\mathrm{FEV}_{1}$, forced respiratory volume in I second; VC, vital capacity; RV, residual volume; TLC, total lung capacity; IC, inspiratory capacity; BMI, body mass index; SD, standard deviation. 
Table 2 Induced sputum cells in mild and moderate COPD subjects

\begin{tabular}{lllll}
\hline & $\begin{array}{l}\text { All patients } \\
(\mathbf{n}=\mathbf{2 9})\end{array}$ & $\begin{array}{l}\text { Patients with BHR } \\
(\mathbf{n}=\mathbf{1 2})\end{array}$ & $\begin{array}{l}\text { Patients without BHR } \\
(\mathbf{n}=\mathbf{1 7})\end{array}$ & P-value* \\
\hline Macrophages (\%) & $6.6(4.6-9.5)$ & $7.5(2.5-8.6)$ & $6.6(5.3-10.9)$ & 0.578 \\
Neutrophils (\%) & $78(73-84)$ & $78.1(68.1-85.5)$ & $79(76.3-83)$ & 0.703 \\
Eosinophils (\%) & $2(1-4.6)$ & $3.4(1.2-5.2)$ & $1.6(0.8-2.1)$ & $0.046 *$ \\
Lymphocytes (\%) & $0.2(0-0.4)$ & $0.1(0-0.4)$ & $0.2(0-0.5)$ & 0.577 \\
Epithelial cells (\%) & $11.5(5.6-15.6)$ & $10.7(5.3-18.1)$ & $12.4(5.6-15.1)$ & 0.836 \\
\hline
\end{tabular}

Notes: Values are expressed as median (interquartile range). Comparisons between variables were determined by unpaired $t$-test. $*$ Patients with BHR vs patients without BHR.

Abbreviation: BHR, bronchial hyperresponsiveness.

patients with sputum eosinophils $\geq 3 \%$ ( $n=9$ ) had higher BHR, more exacerbations in the previous year, and a higher symptom score than patients with sputum eosinophils $<3 \%(P=0.010$, $P=0.019$, and $P=0.031$, respectively) (Table 3 ). No differences in COPD features were observed between patients with and without bronchial reversibility.

When all subjects were considered, no correlations were observed between sputum and functional data. As a point of interest, considering patients with BHR, the cumulative dose of methacholine was negatively related to the symptom score $\left(r_{\mathrm{s}}=-0.76, P=0.005\right)$ and to the number of exacerbations in the previous year $\left(r_{\mathrm{s}}=-0.59, P=0.021\right)$ (Figure 2$)$. Finally, when patients with bronchial reversibility were considered, $\mathrm{FEV}_{1}$ change was positively related to sputum eosinophils $\left(r_{\mathrm{s}}=0.82, P=0.003\right)$ (Figure 3$)$ and negatively related to sputum neutrophils $\left(r_{\mathrm{s}}=-0.66, P=0.030\right)$.

\section{Discussion}

In this study, we evaluated, in mild and moderate COPD patients, BHR, airway inflammation, and bronchial reversibility, three characteristics more frequent in asthmatics but which can also characterize COPD patients.

We found that BHR, sputum eosinophils, and bronchial reversibility were not clustered in only one subgroup of COPD subjects but were spread among most of the subjects, either present alone or associated. Subjects with BHR had

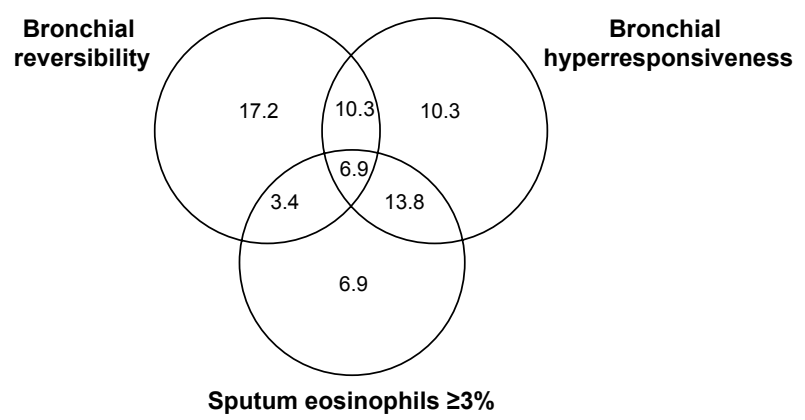

Figure I Venn-diagram showing the percentage distribution of bronchial reversibility, bronchial hyperresponsiveness, and sputum eosinophilia in the COPD subjects enrolled in the study. higher hyperinflation and more sputum eosinophils than those without BHR. The presence of eosinophils in the airways was associated with a higher number of exacerbations in the previous year and a higher symptom score. Methacholine dose was negatively related to the symptom score and the number of exacerbations in the previous year in subjects with BHR, and bronchial reversibility was positively related to sputum eosinophils and negatively to sputum neutrophils.

The novelty of our study is the consideration of BHR, reversibility, and sputum eosinophils together showing that the heterogeneity of the disease could be even wider than thought. BHR, sputum eosinophils, and reversibility are usually present in asthma. If these characteristics would be present in only one subgroup of COPD patients, this could be considered an overlap between COPD and asthma. While in our study we showed that both patients with only one of these characteristics and patients with all of them exist, it would be worthy to follow them to evaluate the impact of these characteristics on the clinical history of the disease.

According to published data, different percentages of COPD patients, from $50 \%$ to up $95 \%$, more frequently females, have $\mathrm{BHR},{ }^{8,30}$ which is associated with more severe disease and a more rapid decline of $\mathrm{FEV}_{1} \cdot{ }^{31}$ We found that $41.3 \%$ of mild and moderate COPD subjects had BHR and that these subjects had higher hyperinflation. Postma and Kerstjens $\mathrm{s}^{32}$ previously demonstrated that BHR in COPD is predominantly associated with RV/TLC.

The importance of evaluating BHR in COPD is due to the fact that BHR was associated with a rapid $\mathrm{FEV}_{1}$ decline, and significantly associated with death from COPD, while an improvement in BHR with fluticasone and fluticasone/ salmeterol was described in COPD patients. ${ }^{33,34}$ BHR in COPD was predominantly associated with sputum eosinophils, independently from the different stimuli used to evaluate it, such as methacholine, mannitol, and AMP. . $^{8,35,36}$ van den Berge et $\mathrm{al}^{8}$ however, through a multivariate analysis, showed that sputum neutrophils and lymphocytes are 
Table 3 BHR, reversibility, symptom score, and exacerbations in COPD patients considered altogether and divided according to sputum eosinophils

\begin{tabular}{|c|c|c|c|c|}
\hline & $\begin{array}{l}\text { All patients } \\
(\mathrm{n}=29)\end{array}$ & $\begin{array}{l}\text { Patients with eosinophils } \\
\geq 3 \%(n=9)\end{array}$ & $\begin{array}{l}\text { Patients with eosinophils } \\
<3 \%(n=20)\end{array}$ & $P$-value* \\
\hline $\mathrm{BHR}(\mu \mathrm{g})$ & $1,600(208-1,600)$ & $100(32-1,600)$ & I,600 (990-I,600) & 0.010 \\
\hline Reversibility (change FEV , in \%) & $5.6(0.3-14.6)$ & $3.0(0-21.1)$ & $5.9(1.1-13.2)$ & 0.862 \\
\hline Symptom score & $8.0(5.0-10.0)$ & $8.0(8.0-9.5)$ & $6.5(4.2-9.5)$ & 0.031 \\
\hline Exacerbations previous year & $0.0(0.0-1.0)$ & $1.0(1.0-1.5)$ & $0.0(0.0-1.0)$ & 0.019 \\
\hline
\end{tabular}

Notes: Values are expressed as median (interquartile range). Comparisons between variables were determined by unpaired $t$-test. $*$ Patients with eosinophils $\geq 3 \%$ vs patients with eosinophils $<3 \%$.

Abbreviations: $\mathrm{BHR}$, bronchial hyperresponsiveness; $\mathrm{FEV}_{1}$, forced respiratory volume in I second.

independent determinants of BHR, and Dima et a $1^{15}$ found a positive correlation between BHR and sputum neutrophils. Other studies showed a weak correlation between BHR and airway inflammation, confirming their dissociation in COPD subjects. ${ }^{37}$ In all our subjects, we found high sputum neutrophils compared to reference values of healthy controls, as expected, but only eosinophils were higher in the BHR group compared to the non-BHR patients. However, we found a few patients with BHR without sputum eosinophilia, confirming that different mechanisms inducing BHR, including the smoking habit, might exist. Smoking is one of the main determinants of BHR and neutrophil recruitment in the airways, and smoking cessation reduces both BHR and airway inflammation. ${ }^{38}$

Sputum eosinophils have been previously described in COPD patients, particularly during exacerbation, ${ }^{39,40}$ and the importance of their evaluation lies in their good response to steroid treatment. We chose $3 \%$ as the cut-off for sputum eosinophilia, considering that it is more reproducible over time. ${ }^{41}$ Although all cut-off points greater than $2 \%$ are reproducible, $3 \%$ cut-off resulted in the highest agreement for distinguishing eosinophilic from noneosinophilic airway inflammation. ${ }^{42}$
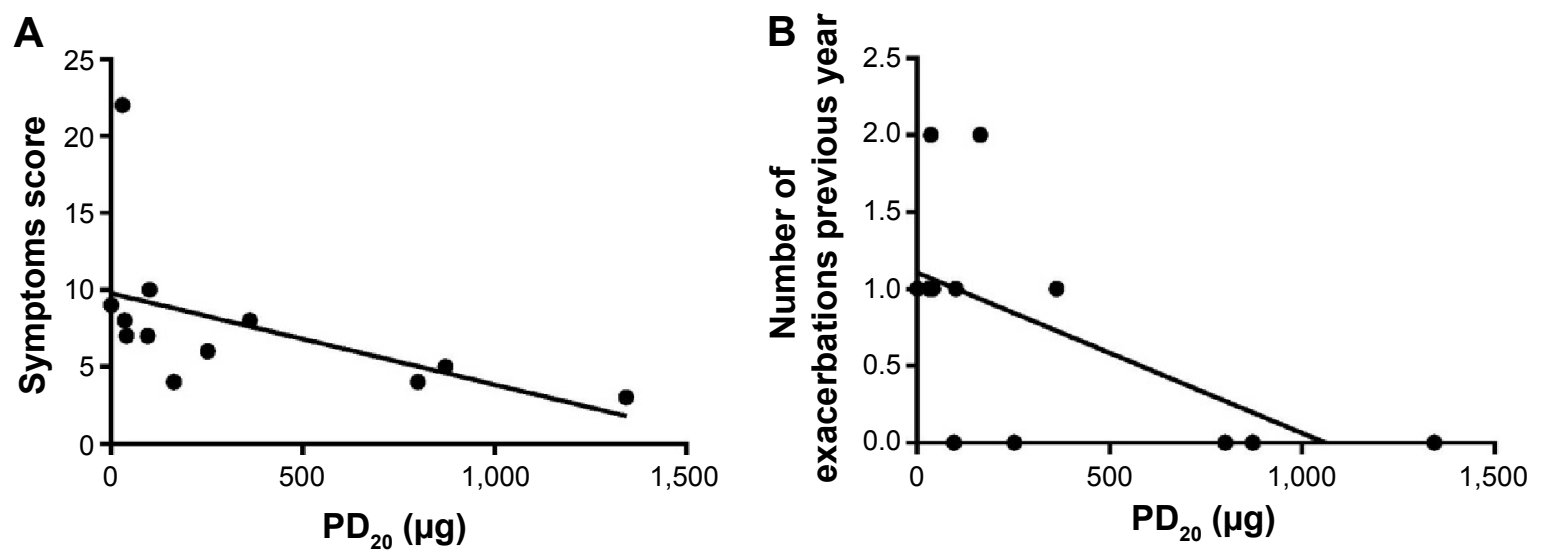

Figure 2 Correlation between the cumulative dose of methacholine $\left(\mathrm{PD}_{20}\right)$ and the score of $\mathrm{COPD}$ symptoms questionnaire $\left(r_{\mathrm{s}}=-0.76, P=0.005\right)(\mathbf{A})$, and the number of exacerbations in the previous year $\left(r_{s}=-0.59, P=0.021\right)(B)$. 


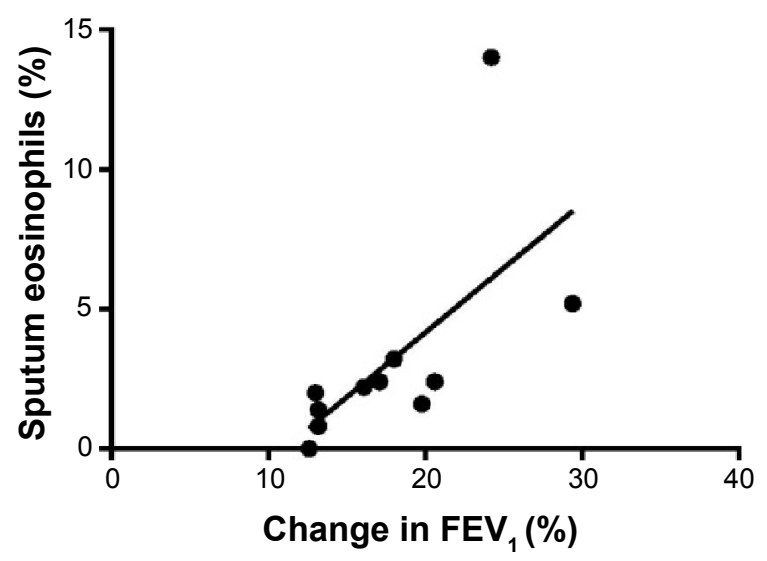

Figure 3 Correlation between changes in post-bronchodilator FEV ( $\%$ baseline) and sputum eosinophils (\%) $\left(r_{s}=0.82, P=0.003\right)$.

Abbreviation: $\mathrm{FEV}_{1}$, forced respiratory volume in I second.

to increase neutrophil recruitment in the airways, which could have masked a mild eosinophil increase. Furthermore, when we considered subjects with bronchial reversibility, sputum neutrophils were negatively related to the magnitude of reversibility, confirming that sputum neutrophilia is a characteristic that is more significant in more severe patients with irreversible bronchial constriction.

Bronchodilator responsiveness seems to be relatively variable, and according to recent published data this phenotype of COPD patients cannot predict clinical relevant outcomes. ${ }^{43}$ However, Albert et al ${ }^{43}$ observed that patients with consistent bronchial reversibility showed a lower exacerbation rate and tended to have fewer hospitalizations due to exacerbation, as compared to patients with consistent bronchial irreversible. Also, in this case the authors did not consider BHR and airway inflammation together with bronchial reversibility.

We would like to emphasize the fact that this is a crosssectional, "real life" study, and all the subjects were outpatients. Exclusion of steroid treated and exacerbated patients limited the number of subjects included. The follow-up of these subjects will give us the opportunity to better evaluate the impact of bronchial reversibility, hyperactivity, and sputum eosinophilia in the long-term outcome of the disease.

In conclusion, we evaluated BHR, sputum airway inflammation, and bronchial reversibility, showing that these characteristics can be present alone or associated in mild-moderate COPD patients. The heterogeneity of COPD has been widely described in recent years, particularly finding different COPD phenotypes. In this context, the evaluation of BHR and sputum airway inflammation, together with bronchial reversibility could be really useful in personalizing therapy and in selection of patients at increased risk of exacerbations. Longitudinal studies are needed to validate these findings and clarify the interplay among BHR, sputum airway inflammation, and bronchial reversibility over time.

\section{Author contributions}

AZ, PP, and AS contributed to design, drafting, and interpretation; FC, EZ, and SC collected data; AZ, FC, and EZ performed statistical analysis. All authors contributed to the revision of the paper and agree to be accountable for all aspects of the work.

\section{Disclosure}

All the authors concurred with the submission and none of them have any conflicts of interest related to this manuscript.

\section{References}

1. Schwartz J, Schindler C, Zemp E, et al. Predictors of methacholine responsiveness in a general population. Chest. 2002;122(3): 812-820.

2. Brutsche MH, Downs SH, Schindler C, et al; SAPALDIA Team. Bronchial hyperresponsiveness and the development of asthma and COPD in asymptomatic individuals: SAPALDIA cohort study. Thorax. 2006;61(8):671-677.

3. Magnussen H, Nowak D. Roles of hyperresponsiveness and airway inflammation in bronchial asthma. Respiration. 1989;55(2): 65-74.

4. Crimi E, Spanevello A, Neri M, Ind PW, Rossi GA, Brusasco V. Dissociation between airway inflammation and airway hyperresponsiveness in allergic asthma. Am J Respir Crit Care Med. 1998;157(1): 4-9.

5. Chinn S, Jarvis D, Luczynska CM, et al. An increase in bronchial responsiveness is associated with continuing or restarting smoking. Am J Respir Crit Care Med. 2005;172(8):156-161.

6. Wise RA, Kanner RE, Lindgren P, et al; Lung Health Study Research Group. The effect of smoking intervention and an inhaled bronchodilator on airways reactivity in COPD: the Lung Health Study. Chest. 2003;124(2):449-458.

7. Tashkin DP, Altose MD, Bleecker ER, et al. The lung health study: airway responsiveness to inhaled methacholine in smokers with mild to moderate airflow limitation. The Lung Health Study Research Group. Am Rev Respir Dis. 1992;145(2 Pt 1):301-310.

8. van den Berge M, Vonk JM, Gosman M, et al. Clinical and inflammatory determinants of bronchial hyperresponsiveness in COPD. Eur Respir J. 2012;40(5):1098-1105.

9. Ronchi MC, Piragino C, Rosi E, Amendola M, Duranti R, Scano G. Role of sputum differential cell count in detecting airway inflammation in patients with chronic bronchial asthma or COPD. Thorax. 1996;51(10):1000-1004.

10. Saetta M, Di Stefano A, Turato G, et al. CD8+ T-lymphocytes in peripheral airways of smokers with chronic obstructive pulmonary disease. Am J Respir Crit Care Med. 1998;157(3 Pt 1):822-826.

11. Brightling CE, Monteiro W, Ward R, et al. Sputum eosinophilia and short-term response to prednisolone in chronic obstructive pulmonary disease: a randomized controlled trial. Lancet. 2000;356(9240): $1480-1485$.

12. Siva R, Green RH, Brightling CE, et al. Eosinophilic airway inflammation and exacerbations of COPD: a randomized controlled trial. Eur Respir J. 2007;29(5):906-913. 
13. Calverley PM, Burge PS, Spencer S, Anderson JA, Jones PW; for the ISOLDE Study Investigators. Bronchodilator reversibility testing in chronic obstructive pulmonary disease. Thorax. 2003;58(8):659-664.

14. Papi A, Romagnoli M, Baraldo S, et al. Partial reversibility of airflow obstruction and increased NO and sputum eosinophilia in chronic obstructive pulmonary disease. Am J Respir Crit Care Med. 2000; 162(5):1773-1777.

15. Dima E, Rovina N, Gerassimou C, Roussos C, Gratziou C. Pulmonary function tests, sputum induction, and bronchial provocation tests: diagnostic tools in the challenge of distinguishing asthma and COPD phenotypes in clinical practice. Int J Chron Obstruct Pulmon Dis. 2010; 5:287-296

16. Carolan BJ, Sutherland ER. Clinical phenotypes of chronic obstructive pulmonary disease and asthma: recent advances. J Allergy Clin Immunol. 2013;131(3):627-634.

17. Burgel PR, Paillasseur JL, Caillaud D, et al; Initiatives BPCO Scientific Committee. Clinical COPD phenotypes: a novel approach using principal component and cluster analyses. Eur Respir J. 2010; 36(3):531-539.

18. Nishimura M, Makita H, Nagai K, et al; Hokkaido COPD Cohort Study Investigators. Annual change in pulmonary function and clinical phenotype in chronic obstructive pulmonary disease. Am J Respir Crit Care Med. 2012;185(1):44-52.

19. Izquierdo-Alonso JL, Rodriguez-Gonzálezmoro JM, de LucasRamos P, et al. Prevalence and characteristics of three clinical phenotypes of chronic obstructive pulmonary disease (COPD). Respir Med. 2013;107(5):724-731.

20. Garcia-Aymerich J, Gómez FP, Benet M, et al; PAC-COPD Study Group. Identification and prospective validation of clinically relevant chronic obstructive pulmonary disease (COPD) subtypes. Thorax. 2011;66(5):430-437.

21. Hardaker KM, Downie SR, Kermode JA, Berend N, King GG, Salome $\mathrm{CM}$. Ventilation heterogeneity is associated with airway responsiveness in asthma but not COPD. Respir Physiol Neurobiol. 2013; 189(1):106-111.

22. Vestbo J, Hurd SS, Agusti AG, et al. Global strategy for the diagnosis, management, and prevention of chronic obstructive pulmonary disease: GOLD executive summary. Am J Respir Crit Care Med. 2013 187(4):347-365.

23. Beier J, Kirsten A-M, Mróz R, et al. Efficacy and safety of aclidinium bromide compared with placebo and tiotropium in patients with moderate-to-severe chronic obstructive pulmonary disease: results from a 6-week, randomized, controlled Phase IIIb study. COPD. 2013; 10(4):511-522.

24. Pellegrino R, Viegi G, Brusasco V, et al. Interpretative strategies for lung function tests. Eur Respir J. 2005;26(5):948-968.

25. Quanjer PH, Tammeling GJ, Cotes JE, Pedersen OF, Peslin R, Yernault JC. Lung volumes and forced ventilatory flows. Report Working Party Standardization of Lung Function Tests, European Community for Steel and Coal. Official Statement of the European Respiratory Society. Eur Respir J Suppl. 1993;16:5-40.

26. Cotes JE, Chinn DJ, Quanjer PH, Roca J, Yernault JC. Standardization of the measurement of transfer factor (diffusing capacity). Report Working Party Standardization of Lung Function Tests, European Community for Steel and Coal. Official Statement of the European Respiratory Society. Eur Respir J Suppl. 1993;16:41-52.
27. Sterk PJ, Fabbri LM, Quanjer PH, et al. Standardized challenge testing with pharmacological, physical and sensitizing stimuli in adults. Eur Respir J. 1993;6(Suppl 16):53s-83s.

28. Pignatti P, Zanini A, Della Patrona S, Gumiero F, Cherubino F, Spanevello A. Pulmonary function testing: sputum and exhaled breath analysis. In: Palange P, Simonds AK, editors. ERS Handbook of Respiratory Medicine. 2nd ed. Sheffield, UK: European Respiratory Society; 2013:103-108.

29. European Respiratory Task Force. Standardised methodology of sputum induction and processing. Eur Respir J. 2002;20(Suppl 37):1s-55s.

30. Yan K, Salome CM, Woolcock AJ. Prevalence and nature of bronchial hyperresponsiveness in subjects with chronic obstructive pulmonary disease. Am Rev Respir Dis. 1985;132(1):25-29.

31. Tashkin DP, Altose MD, Connett JE, Kanner RE, Lee WW, Wise RA Methacholine reactivity predicts changes in lung function over time in smokers with early chronic obstructive pulmonary disease. The Lung Health Study Research Group. Am J Respir Crit Care Med. 1996;153 (6 Pt 1):1802-1811.

32. Postma DS, Kerstjens HA. Characteristics of airway hyperresponsiveness in asthma and chronic obstructive pulmonary disease. Am J Respir Crit Care Med. 1998;158(5 Pt 3):S187-S192.

33. Hospers JJ, Postma DS, Rijcken B, Weiss ST, Schouten JP. Histamine airway hyper-responsiveness and mortality from chronic obstructive pulmonary disease: a cohort study. Lancet. 2000;356(9238):1313-1317.

34. Lapperre TS, Snoeck-Stroband JB, Gosman MM, et al; Groningen Leiden Universities Corticosteroids in Obstructive Lung Disease Study Group. Effect of fluticasone with and without salmeterol on pulmonary outcomes in chronic obstructive pulmonary disease: a randomized trial Ann Intern Med. 2009;151(8):517-527.

35. de Nijs SB, Fens N, Lutter R, et al. Airway inflammation and mannitol challenge test in COPD. Respir Res. 2011;12:11.

36. Rutgers SR, Timens W, Tzanakis N, et al. Airway inflammation and hyperresponsiveness to adenosine 5-monophosphate in chronic obstructive pulmonary disease. Clin Exp Allergy. 2000;30(5):657-662.

37. Lapperre TS, Snoeck-Stroband JB, Gosman MM, et al; Groningen and Leiden Universities Corticosteroids in Obstructive Lung Disease Study Group. Dissociation of lung function and airway inflammation in chronic obstructive pulmonary disease. Am J Respir Crit Care Med. 2004;170(5):499-504

38. Scichilone N, Battaglia S, La Sala A, Bellia V. Clinical implications of airway hyperresponsiveness in COPD. Int J Chron Obstruct Pulmon Dis. 2006;1(1):49-60.

39. Jeffery PK. Pathology of asthma and COPD: a synopsis. Eur Respir Rev. 1997; 7:111-118.

40. Saetta M. Central airways inflammation in the development of COPD. Eur Respir Rev. 1997;7:109-110.

41. van Veen IH, Ten Brinke A, Gauw SA, Sterk PJ, Rabe KF, Bel EH. Consistency of sputum eosinophilia in difficult-to-treat asthma: a 5-year follow-up study. J Allergy Clin Immunol. 2009;124(3):615-617.

42. Simpson JL, McElduff P, Gibson PG. Assessment and reproducibility of non-eosinophilic asthma using induced sputum. Respiration. 2010;79(2):147-151.

43. Albert P, Agusti A, Edwards L, et al. Bronchodilator responsiveness as a phenotypic characteristic of established chronic obstructive pulmonary disease. Thorax. 2012;67(8):701-708.
International Journal of COPD

\section{Publish your work in this journal}

The International Journal of COPD is an international, peer-reviewed journal of therapeutics and pharmacology focusing on concise rapid reporting of clinical studies and reviews in COPD. Special focus is given to the pathophysiological processes underlying the disease, intervention programs, patient focused education, and self management protocols.

\section{Dovepress}

This journal is indexed on PubMed Central, MedLine and CAS. The manuscript management system is completely online and includes a very quick and fair peer-review system, which is all easy to use. Visit http://www.dovepress.com/testimonials.php to read real quotes from published authors. 